\title{
Development of Field Excavator with Embedded Force Measurement
}

\author{
K. Johnson ${ }^{1}$, C. Creager ${ }^{2}$, A. Izadnegahdar ${ }^{3}$, S. Bauman ${ }^{4}$, C. Gallo ${ }^{5}$, P. Abel ${ }^{6}$ \\ ${ }^{1}$ NASA Glenn Research Center (GRC), Mail Stop 86-12, 21000 Brookpark Road, Cleveland, \\ OH 44135; Ph (216) 433-3571; email: kyle.a.johnson@nasa.gov \\ ${ }^{2}$ NASA GRC, Mail Stop 23-3; Ph (216) 433-6303; email: colin.m.creager@nasa.gov \\ ${ }^{3}$ NASA GRC, Mail Stop 500ASRC; Ph (216) 433-6163; email: alain.izadnegahdar- \\ 1@nasa.gov \\ ${ }^{4}$ NASA GRC, Mail Stop 23-2; Ph (216) 433-3826; email:steven.w.bauman@nasa.gov \\ ${ }^{5}$ NASA GRC, Mail Stop 86-1; Ph (216) 433-8823; email:christopher.a.gallo@nasa.gov \\ ${ }^{6}$ NASA GRC, Mail Stop 23-2; Ph (216) 433-6063; email: phillip.b.abel@nasa.gov
}

\begin{abstract}
A semi-intelligent excavation mechanism was developed for use with the NASA-built Centaur 2 rover prototype. The excavator features a continuously rotatable large bucket supported between two parallel arms, both of which share a single pivot axis near the excavator base attached to the rover. The excavator is designed to simulate the collection of regolith, such as on the Moon, and to dump the collected soil into a hopper up to one meter tall for processing to extract oxygen. Because the vehicle can be autonomous and the terrain is generally unknown, there is risk of damaging equipment or using excessive power when attempting to extract soil from dense or rocky terrain. To minimize these risks, it is critical for the rover to sense the digging forces and adjust accordingly. It is also important to understand the digging capabilities and limitations of the excavator.

This paper discusses the implementation of multiple strain gages as an embedded force measurement system in the excavator's arms. These strain gages can accurately measure and resolve multi-axial forces on the excavator. In order to validate these sensors and characterize the load capabilities, a series of controlled excavation tests were performed at Glenn Research Center with the excavator at various depths and cut angles while supported by a six axis load cell. The results of these tests are both compared to a force estimation model and used for calibration of the embedded strain gages. In addition, excavation forces generated using two different types of bucket edge (straight vs. with teeth) were compared.
\end{abstract}




\section{INTRODUCTION}

With increasing machine sophistication taken for granted, robotic participation in human space exploration will increasingly play a key role in mission risk reduction, even enabling otherwise untenable activities or automating tedious but necessary chores. Future robots in the human spaceflight program can serve as crew precursors, or as robots working along cooperatively during crewed mission phases. The robotic research activity sponsoring the work presented here is partially motivated by the broad range of tasks, precursor and cooperative, that a versatile and highly mobile platform can accomplish with exchangeable payloads.

The "Centaur 2" (C2) platform is a compact vehicle with four independently steered and actuated wheel pods, allowing the vehicle to pivot in place and tilt in two directions (NASA JSC 2010). It is designed to interface with and carry the anthropomorphic robot torso "Robonaut 2". There are two nearly identical interface mounting locations on opposite sides of the vehicle body; each provides both power and data channel access. To explore soil moving capabilities of this versatile platform, an articulated excavator was required for transporting raw material (soil) to an analog volatile extraction processor.

Robotic precursor in-situ resource utilization (ISRU) production of oxygen and/or other propulsion combustibles could safely enable missions that are otherwise too massive. Both the bucket volume and dumping height capability of the excavator were designed to supply input to an existing ISRU processing plant design. Other precursor activities requiring soil manipulation include habitat site preparation, berm building to mitigate rocket exhaust impingement, and potentially even regolith collection for extraction of metals. A concern for soil excavation under reduced gravity is whether the vehicle can generate sufficient reaction force (e.g. traction) to effectively operate. For efficient, autonomous excavation to be shown feasible, a study of the forces encountered was required as well as the necessary control algorithms.

\section{DESIGN OF EXCAVATOR}

The "NASA Glenn Digger" is the excavator built specifically for the Centaur 2 robot (NASA JSC 2010). developed by the NASA Johnson Space Center (JSC). The Digger, when mounted to $\mathrm{C} 2$, was designed to shovel existing lose regolith from the terrain, similar to a traditional tractor "front loader", then raise the loaded bucket up and deposit the load into a hopper of a predefined height. The hopper would prospectively be the input to a machine that would produce oxygen from lunar regolith that is needed for long-term lunar habitation.

\section{Requirements}

The following requirements were based upon design and operational specifications for the Centaur 2 as well as to optimize digging strength and ease of use.

1. Must attach to the $\mathrm{C} 2$ bolt pattern.

2. Must not interfere with $\mathrm{C} 2$ wheel steering or suspension motion when mounted at the front or rear of $\mathrm{C} 2$

3. Mass limit for the whole device, with maximum bucket load: $150 \mathrm{~kg}$. 
4. The bucket shall collect and hold at least $32.6 \mathrm{~kg}$ of lunar simulant.

5. Mechanism must stiffly lower the bucket into lunar simulant, and hold a set digging depth and rake angle during forward vehicle motion for regolith collection.

6. Must be capable of both forward and reverse vehicle digging motion.

7. Bucket must elevate, full of regolith, and dump into a defined hopper with an edge height of one meter.

8. Working components such as the motor, gears, sprockets, chains, brakes, and torque limiters, etc. should be enclosed.

9. A controller and demonstrated control logic must be included, and must be compatible with JSC heritage.

\section{Design}

The final design of the Digger consists of 2 parallel arms coupled together and supporting a bucket on one end. In addition to the bucket rotating, the arms are rotationally actuated at their "shoulder", giving it two degrees of freedom (see Figure $1)$.

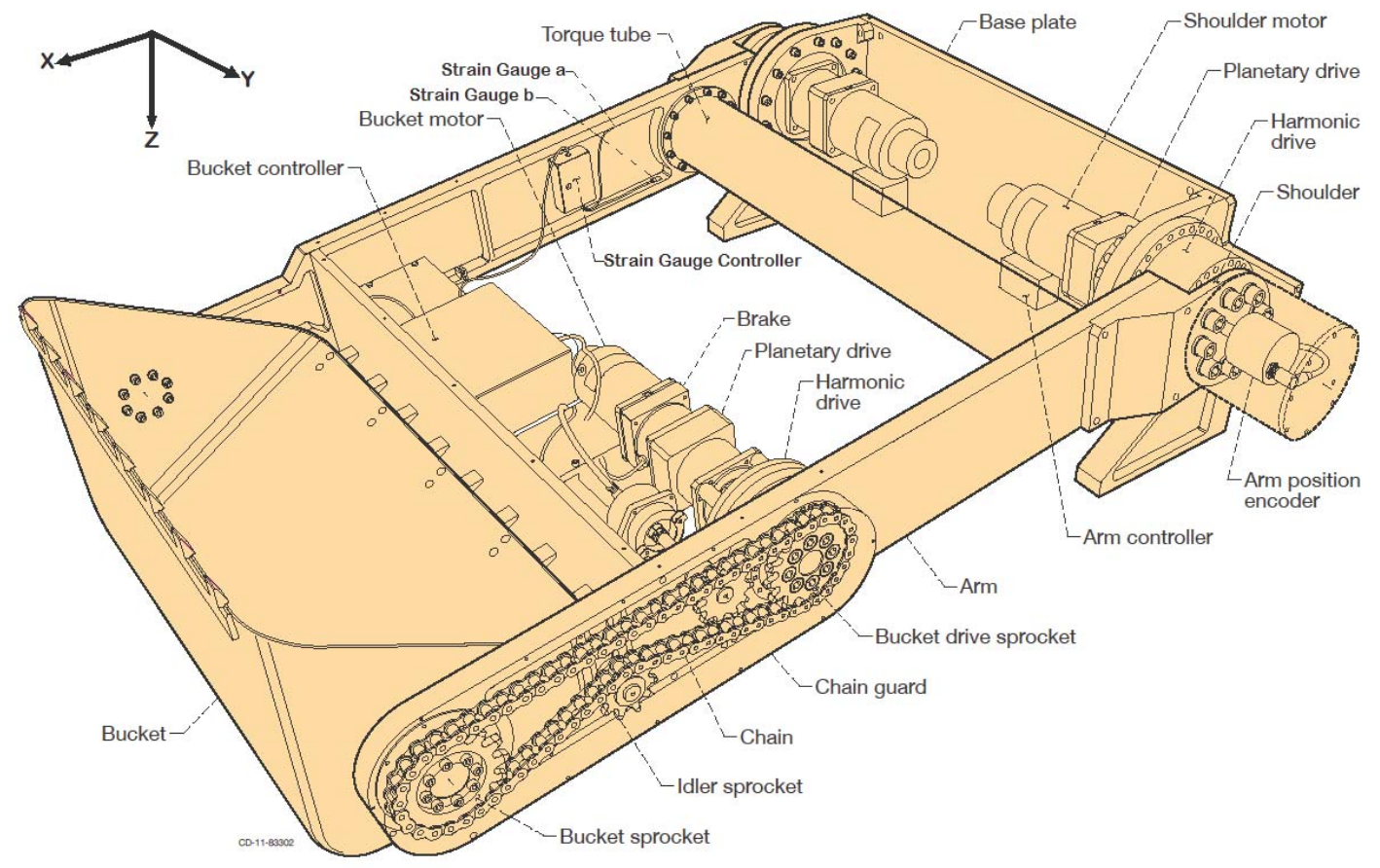

Figure 1. Pictorial representation of final Digger design

The shoulder is powered by two shoulder drive motors each attached to a 10:1 planetary and 160:1 harmonic gearbox for a final ratio of 1600:1. The motors are each controlled by an AMC motor driver and operate in a master slave configuration where the slave motor follows the position of the master. A power-off enabled brake is installed on the arm master drive to provide a holding torque when power is turned off. The arms are constructed from machined aluminum pieces and are tied together with a torque tube to help distribute uneven loading. The bucket motor and motor controller are located on a shelf midway through the arm. The transmission for the 
bucket also consists of a 10:1 planetary and smaller 160:1 harmonic gearbox. A chain attaches the output of the harmonic drive to the bucket. This configuration allows for the motors and drives to be contained within the arm and protected. The bucket has curved edges, where the sides join the main length panels. This helps assure evacuation of the bucket, and makes the structure stronger. Teeth were added to both leading edges of the bucket to mitigate excavation forces. The final mass of the Digger is $94 \mathrm{~kg}, 56 \mathrm{~kg}$ less than the allowable limit.

The main controller is attached to the base plate between the shoulder drive motors. The purpose of the main controller is to coordinate the movements of the arm and bucket with $\mathrm{C} 2$ 's requests while reading the sensors and providing feedback to C2. The sensors on the Digger are two absolute position sensors on the arm and bucket, a relative position encoder on each motor, and four full bridge strain gauges, two on each arm. All sensor data is converted to serial data and transmitted to the main controller.

\section{IMPLEMENTATION OF STRAIN GAUGES}

In order to measure the forces exerted on the arms of the excavator, four full bridge strain gauges were attached to the arms, two on each side. In normal operation, the gravitational force of a load will introduce forces in $\mathrm{Z}$ and $\mathrm{X}$ directions (See Figure 4). Measurements from four gauges and some algebraic calculations allow for determining forces in each independent direction. When the arms of the excavator are moved upwards and positioned at some angle relative to the horizontal line, the gravitational load force will be decomposed to both directions relative to the arm.

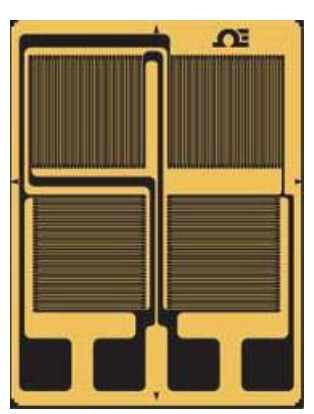

Figure 2. Strain gauge resistor pattern orientation.

Each bridge consists of four $1 \mathrm{~K} \Omega$ resistors that change value with strain. The orientation of resistor line patterns are such that two perpendicular directions can be detected and measured (See Figure 2). The gauges selected for this application have thermal expansion coefficient compatible with aluminum. In addition, an electronic temperature sensor was installed on the electronic board for temperature drift compensation and cancellation.

The gauges were installed on the excavator arm flanges with epoxy adhesive. The gauge resistance change is measured using a custom electronic board. This circuit has a

gain of about 500. After amplification and filtering, the voltage is converted to a 10-bit digital number. This provides $0.1 \%$ resolution. Readings from each independent gauge are transmitted to a central controller via a serial port (See Figure 3). The central controller is in charge of

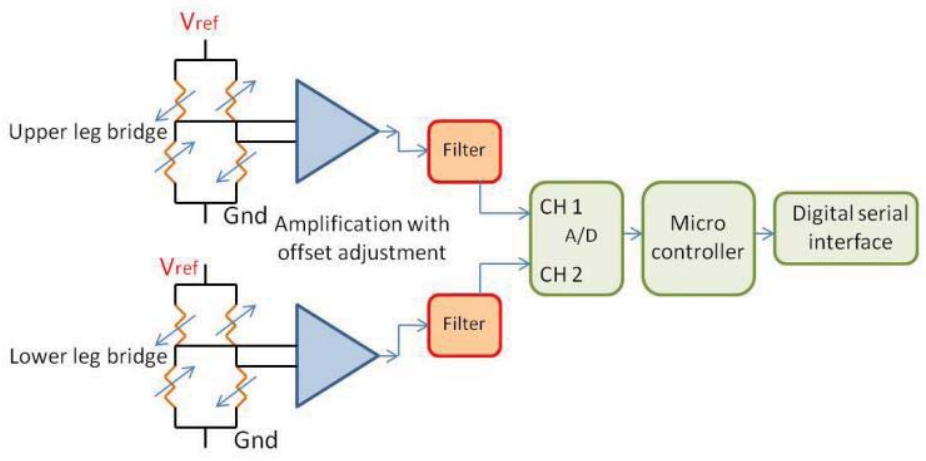

Figure 3. Dual strain gauge amplifier and digital transmitter electronic circuit block diagram 
mathematical calculations and determination of force vectors.

This board operates from a single 5 to 12 VDC and can send data at a maximum rate of 115,200 bauds. If necessary, over 100 data points per second can be sampled. One board was installed on each side of the excavator and transmits data from its two adjacent gauges.

\section{Force analysis}

The load path for the Digger starts at the bucket and ends up at C2. Excavation loads are transferred to the arm through the bucket bearings and then reacted at the "shoulder" joint. A free body diagram of the load transfer can be found in Figure 4 and a description of the variables follow in Table 1.

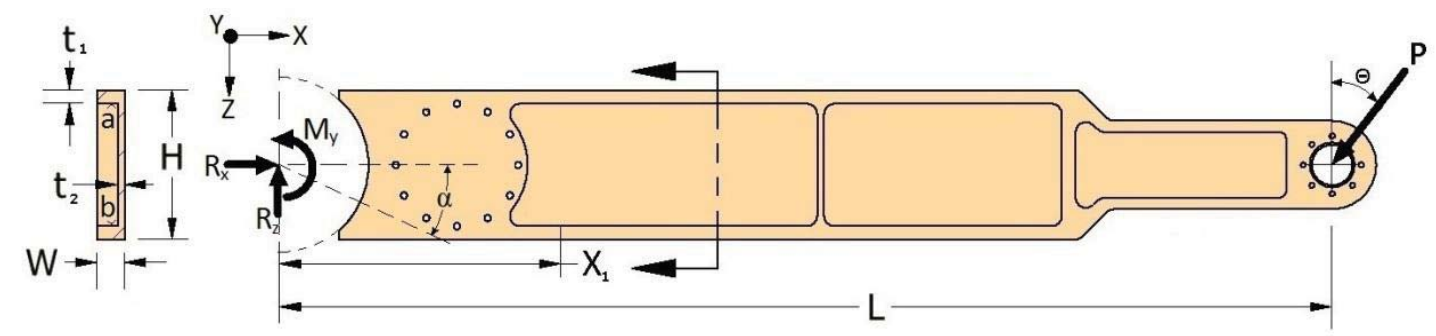

Figure 4. Free body diagram for Digger arm

\begin{tabular}{c|lc} 
Symbol & \multicolumn{1}{c}{$\begin{array}{c}\text { Table 1. System variables and their values } \\
\text { Description }\end{array}$} & Value \\
\hline $\mathrm{L}$ & Length of Digger arm between rotation points & $982.7 \mathrm{~mm}$ \\
\hline $\mathrm{X}_{1}$ & Length from rotational axis to strain gauges & $228.6 \mathrm{~mm}$ \\
\hline $\mathrm{W}$ & Width of the cross section where the strain gauges are attached & $25.4 \mathrm{~mm}$ \\
\hline $\mathrm{H}$ & Height of the cross section where the strain gauges are attached & $139.7 \mathrm{~mm}$ \\
\hline $\mathrm{t}_{1}$ & Thickness of the top and bottom flange & $12.7 \mathrm{~mm}$ \\
\hline $\mathrm{t}_{2}$ & Thickness of the web between flanges & $6.35 \mathrm{~mm}$ \\
\hline $\mathrm{P}$ & Load transferred to the arm from the bucket & Unknown N \\
\hline $\mathrm{R}_{\mathrm{x}}$ & Reaction force in the X direction & $\mathrm{N}$ \\
\hline $\mathrm{R}_{\mathrm{z}}$ & Reaction force in the Z direction & $\mathrm{Nm}$ \\
\hline $\mathrm{M}_{\mathrm{y}}$ & Reaction moment about the Y axis & $-90^{\circ}<\theta<90^{\circ}$ \\
\hline$\theta$ & Angle the load acts on the arm & $-40^{\circ}<\alpha<90^{\circ}$ \\
\hline$\alpha$ & Angle of the arm relative to X axis & $\mathrm{N} / \mathrm{A}$ \\
\hline $\mathrm{a}$ & Label for the upper strain gauge & $\mathrm{N} / \mathrm{A}$ \\
\hline $\mathrm{b}$ & Label for the lower strain gauge & $1371 \mathrm{~mm}$ \\
\hline $\mathrm{A}$ & Cross sectional area at strain gauge location & $3.4 \times 10^{6} \mathrm{~mm}^{4}$ \\
\hline $\mathrm{I}$ & Moment of Inertia about the neutral axis in the X direction & $70 \mathrm{Gpa}$
\end{tabular}

By knowing the strain at locations "a" and " $b$ " the load on the bucket can be calculated using beam theory. The component force equations are,

$\mathrm{P}_{\mathrm{x}}=\mathrm{A} \cdot \mathrm{E} \cdot\left(\varepsilon_{\mathrm{b}}+\varepsilon_{\mathrm{a}}\right) / 2$ Newtons

$\mathrm{P}_{\mathrm{z}}=2 \cdot \mathrm{I} \cdot \mathrm{E} \cdot\left(\varepsilon_{\mathrm{b}}-\varepsilon_{\mathrm{a}}\right) /\left(\left(\mathrm{L}-\mathrm{X}_{1}\right)\left(\mathrm{H}-\mathrm{t}_{1}\right)\right)$ Newtons $\quad$ (Equation 2)

(Equation 1) 
Using equations 1 and 2 and substituting values, the load transferred to the arm on each side is as follows:

$\mathrm{P}=\left(.54 \times 10^{6} \varepsilon_{\mathrm{b}}{ }^{2}+.88 \times 10^{6} \varepsilon_{\mathrm{b}} \cdot \varepsilon_{\mathrm{a}}+.54 \times 10^{6} \varepsilon_{\mathrm{a}}{ }^{2}\right)^{1 / 2}$ Newtons (Equation 3)

$\theta=\tan ^{-1}\left(9.658\left(\varepsilon_{\mathrm{b}}+\varepsilon_{\mathrm{a}}\right) /\left(\varepsilon_{\mathrm{b}}-\varepsilon_{\mathrm{a}}\right)\right)$ degrees

The total load on the bucket is the sum of the loads calculated by the left and right strain gauges. This calculation neglects forces in the $\mathrm{Y}$ direction as these are negligible in normal operations.

The forces transferred to the arm are in a local coordinate system with $\mathrm{X}$ running along the centroidal axis. The reaction forces are measured with respect to C2's coordinate system which is independent of the arms location. The angle of the arm relative to the plane normal to gravity is represented by $\alpha$ and is measured in degrees. The reaction force equations at the mounting plate of $\mathrm{C} 2$ are as follows:

$\mathrm{R}_{\mathrm{x}}=\mathrm{P} \cdot \sin (\theta-\alpha)$ Newtons

(Equation 5)

$\mathrm{R}_{\mathrm{z}}=\mathrm{P} \cdot \cos (\theta-\alpha)$ Newtons

(Equation 6)

$\mathrm{M}_{\mathrm{y}}=\mathrm{Pz} \cdot \mathrm{L}$ Newton meters

\section{DIGGER LOAD TESTING}

In order to calibrate the strain gauges and to evaluate the load carrying capacity of the Digger, a series of tests were performed at GRC involving driving the bucket through various depths of Lunar strength simulant at two different rake angles. These tests essentially simulate the Digger excavating terrain on the Moon, minus the gravitational effects. A model developed at GRC which uses the Balovnev equations (Balovnev 1983) to estimate load on the bucket was also run for these same conditions and compared to the actual forces measured.

\section{Test setup}

Testing was conducted in an excavation rig at GRC which consists of a beam that moves horizontally across a large soil bin (See Figure 5). On this beam is a carriage which can be raised and lowered to precise heights; the Digger was mounted to this carriage through a six-axis load cell. Mounted above the terrain just in front of the bucket are five lasers projecting lines along the soil surface. As the beam is driven, high definition video was taken of these laser projections to get a threedimensional profile of the soil pile-up (See Figure 6). Since the focus of this paper is on load testing, the profiling results are not discussed here.

A sand mixture developed at GRC called "GRC-3" was used for these tests. This particular mixture represents the terrain strength of the Lunar regolith with the addition of fine silt particles, which allow for more conservative excavation testing (small silt particles create a denser and more cohesive terrain). Before conducting each excavation test, the terrain was prepared to a loose condition with tines, then leveled. The terrain properties are listed in Table 3.

A typical test consists of manually digging a trench into which the bucket would be lowered to a desired depth, and the rake angle (the angle of the bottom of the bucket relative to the terrain surface) would be adjusted to the desired setting. 
The Digger was then driven with the beam at a constant rate of $5 \mathrm{~cm} / \mathrm{s}$ for approximately $1.2 \mathrm{~m}$. During this time, load data was collected from the 6-axis load cell, as was strain gauge output from the Digger arms. A comparison between a smooth bucket edge and a toothed edge was also performed.

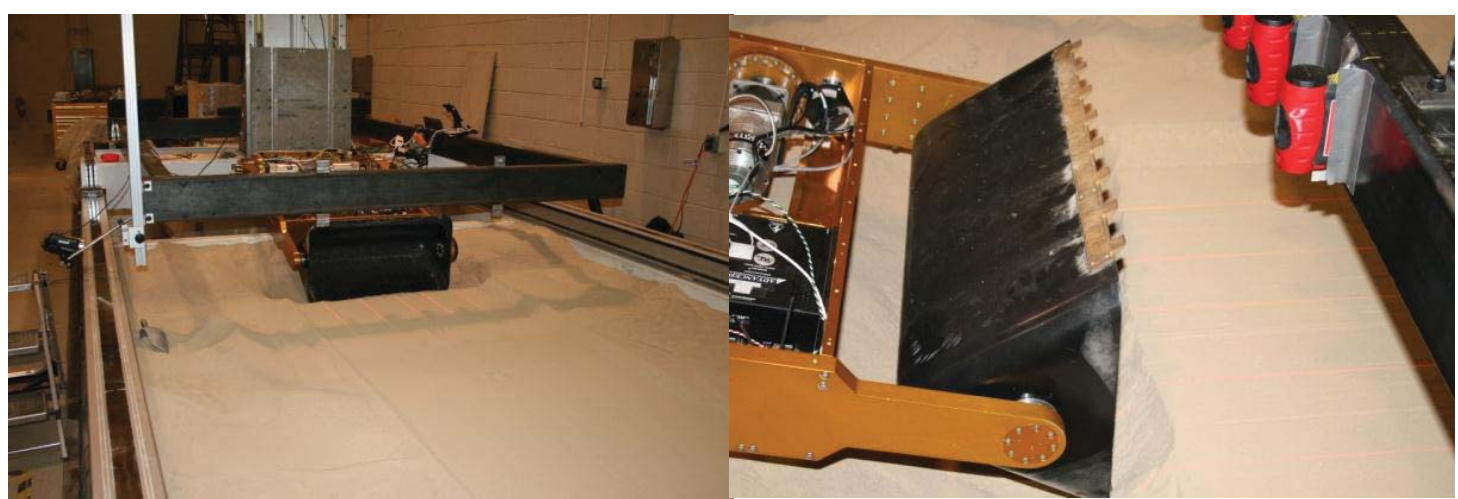

Figure 5. Excavator lowered to desired depth and rake angle pre-test.

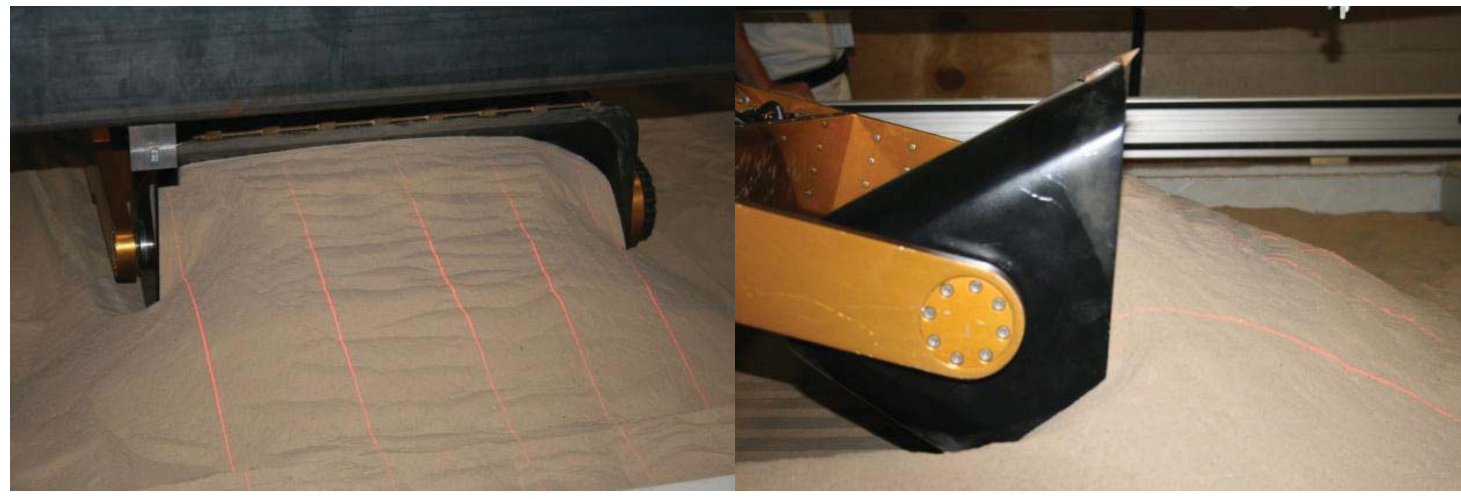

Figure 6. Soil pile-up with laser profiling post-test.

\section{Test Results}

Force values were collected in the vertical and horizontal direction. From this data, the moment on the Digger arm and bucket can be calculated. A sample plot of time vs. force is shown in Figure 7.

Average values for load were calculated for each test; however because the distance traveled is not consistent and load increases relatively linearly with distance, average force is not a reliable metric. Instead, the estimated rate at which force increased with distance (using a linear fit) was used for comparison. A summary of the results is shown in Table 2. From these early tests it does appear that having a toothed edge lowers the required forces for excavation, however more tests would be needed to derive solid conclusions. It is also evident that a larger rake angle lowers the vertical load rate but raises the horizontal load rate, as expected. Though more data would be beneficial, these results can be used to estimate the forces and moments on the Digger when excavating. 


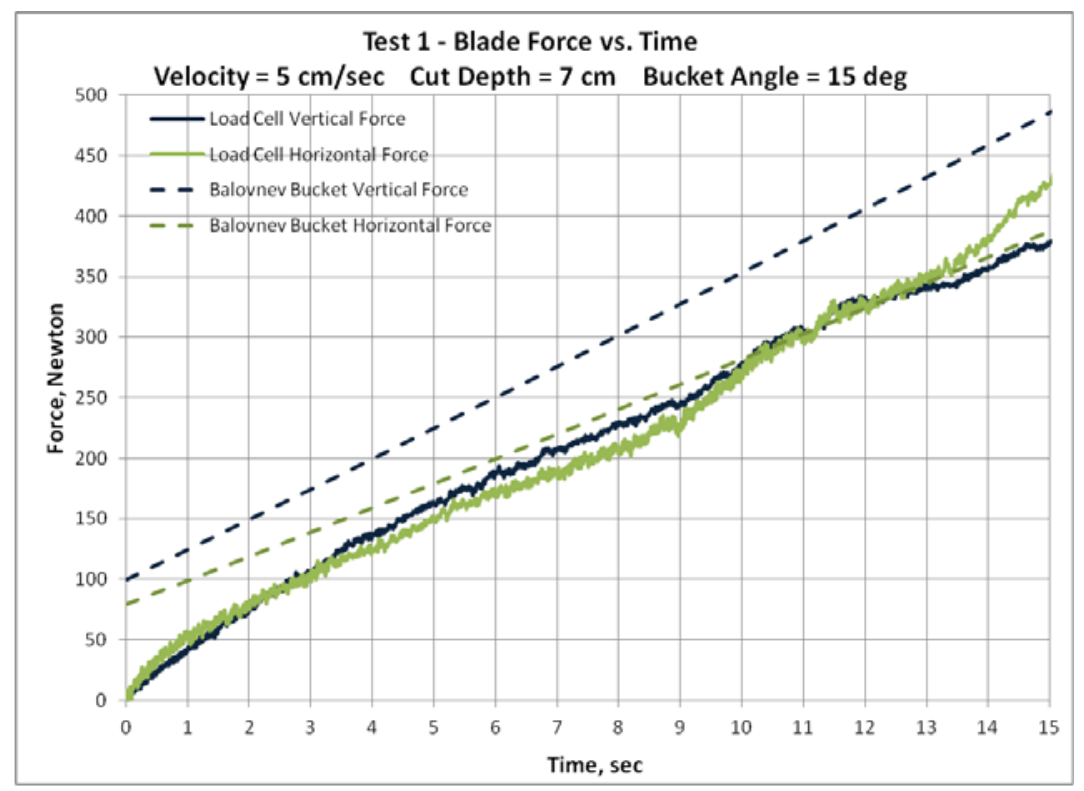

Figure 7. Sample force data from load cell and model

Table 2. Results from Digger Testing

\begin{tabular}{|c|c|c|c|c|c|c|c|c|c|c|c|}
\hline \multirow{2}{*}{ 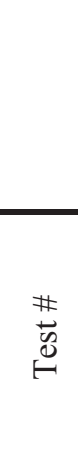 } & \multirow[b]{2}{*}{ 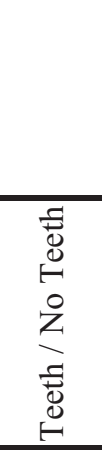 } & \multirow[b]{2}{*}{ 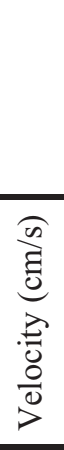 } & \multirow[b]{2}{*}{ 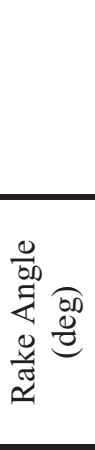 } & \multirow[b]{2}{*}{ 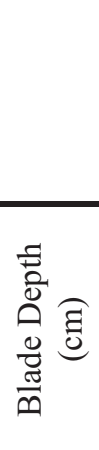 } & \multirow[b]{2}{*}{ 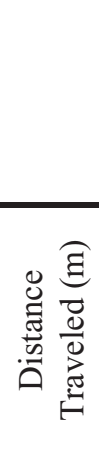 } & \multicolumn{2}{|c|}{$\begin{array}{l}\text { Average } \\
\text { Rate from } \\
\text { Load Cell }\end{array}$} & \multicolumn{2}{|c|}{$\begin{array}{c}\text { Average } \\
\text { Force from } \\
\text { Load Cell }\end{array}$} & \multicolumn{2}{|c|}{$\begin{array}{c}\text { Average } \\
\text { Force from } \\
\text { Balovnev } \\
\text { Equations } 4,5\end{array}$} \\
\hline & & & & & & 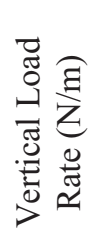 & 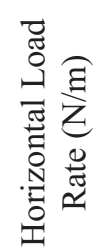 & 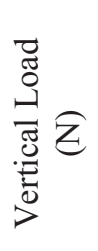 & 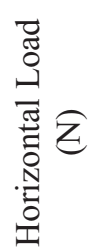 & 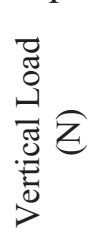 & 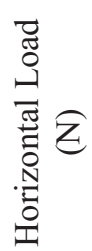 \\
\hline 1 & $\begin{array}{l}\text { No } \\
\text { Teeth }\end{array}$ & 5 & 15 & 7 & 0.76 & 488.5 & 516.2 & 215 & 213 & 292 & 233 \\
\hline 2 & $\begin{array}{l}\text { No } \\
\text { Teeth }\end{array}$ & 5 & 15 & 5 & 1.39 & 280.9 & 312.3 & 245 & 232 & 248 & 198 \\
\hline 3 & $\begin{array}{c}\text { No } \\
\text { Teeth }\end{array}$ & 5 & 15 & 3 & 1.47 & 168.3 & 145.2 & 129 & 131 & 104 & 83 \\
\hline 4 & $\begin{array}{l}\text { No } \\
\text { Teeth }\end{array}$ & 5 & 30 & 5 & 1.37 & 160.6 & 367.1 & 146 & 312 & 154 & 209 \\
\hline 5 & $\begin{array}{l}\text { No } \\
\text { Teeth }\end{array}$ & 5 & 30 & 7 & 1.22 & 142.9 & 639.9 & 170 & 445 & 245 & 333 \\
\hline 6 & Teeth & 5 & 15 & 7 & 1.36 & 267.1 & 356.5 & 230 & 274 & 371 & 297 \\
\hline 7 & Teeth & 5 & 30 & 7 & 1.18 & 96 & 679.3 & 178 & 422 & 245 & 333 \\
\hline
\end{tabular}


Using the data from the load cells and the data collected from the strain gauges (along with Equations 3-6) it was possible to calculate the reaction forces as measured by the strain gauges. Sample results can be seen in Figure .
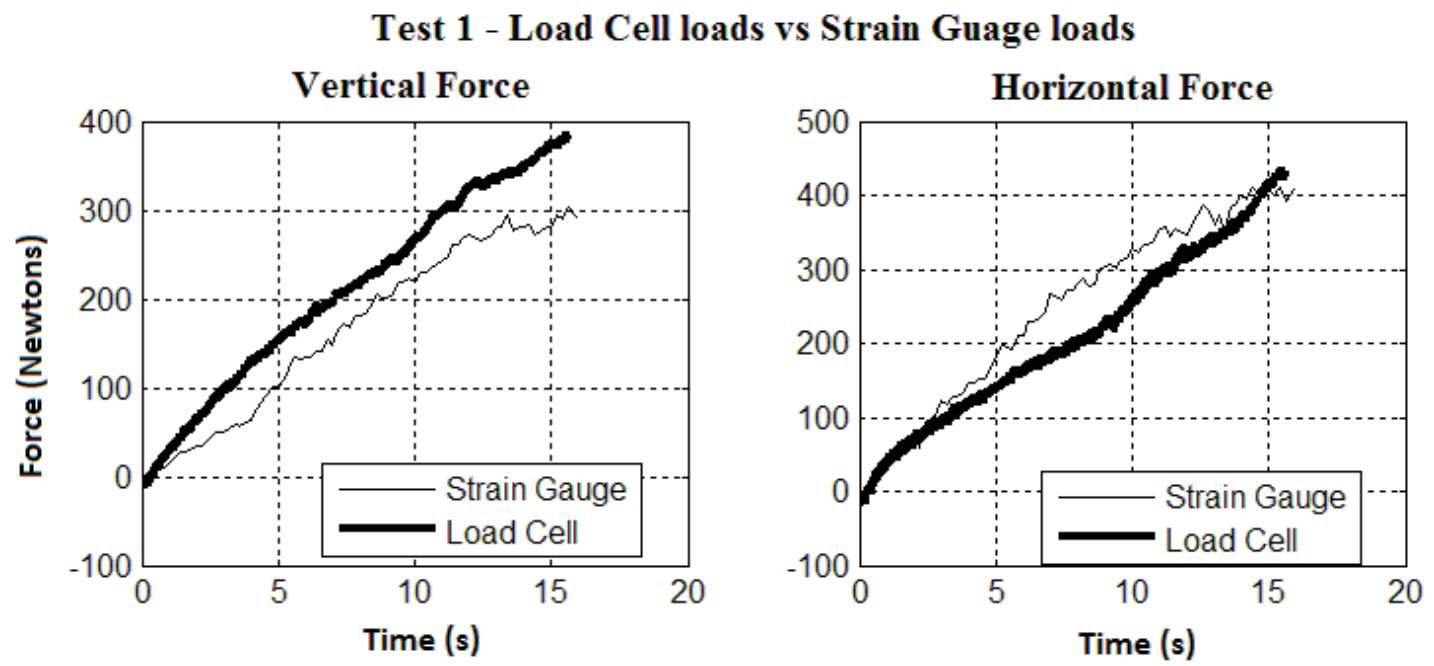

Figure 8. Calculated reaction forces using strain gauges

The calculated loads follow very closely to the load cell outputs. Using the measured strain and the derived equations, load in the bucket and load on the Centaur vehicle can be estimated. Knowing these forces can help prevent damage to the vehicle or Digger during excavation operations.

\section{Model Validation}

A model has been developed at GRC that uses the Balovnev equations (Balovnev 1983) to predict the forces on an excavating unit in known conditions, given the geometry of the bucket and the terrain parameters (see Table 3). The data from these Digger load tests was used for validation. Figure 7 includes a sample of projected forces over time for the specific conditions. By taking distance traveled into account in the model, the average force values can be used for validation as well, as shown in Table 2 .

Table 3. Parameters for Modeling

\begin{tabular}{|c|c|}
\hline \multicolumn{2}{|c|}{ Parameters for Modeling } \\
\hline Acceleration due to Gravity & $9.81 \mathrm{~m} / \mathrm{s}^{2}$ \\
\hline Bucket Width & $0.692 \mathrm{~m}$ \\
\hline Bucket Length & $0.308 \mathrm{~m}$ \\
\hline Bucket Height & $0.330 \mathrm{~m}$ \\
\hline Blade Radius & $1.0 \mathrm{~m}$ \\
\hline Side Plate Thickness & $0.004 \mathrm{~m}$ \\
\hline Blunt Edge Thickness & $0.004 \mathrm{~m}$ \\
\hline Soil Cohesion & $1.00 \mathrm{~N} / \mathrm{m}^{2}$ \\
\hline Soil Internal Friction Angle & $31.5 \mathrm{deg}$ \\
\hline Soil Specific Mass & $1576 \mathrm{~kg} / \mathrm{m}^{3}$ \\
\hline
\end{tabular}




\section{CONCLUSION}

As seen in the results, adding strain gauges to the Glenn Digger provides a good estimate of reaction forces at the Centaur 2 vehicle. Also from these measurements, other reaction forces can be established, such as the load carried in the bucket. The location of the strain gauges is important for this design. The highest force resolution is capable from attaching the strain gauges at the highest strain location. Also, since two strain bridges are used on each arm, forces can be resolved in any direction.

By knowing the load in the bucket, efficient and automated digging processes can be developed. For instance, a sample objective for Centaur 2 might be to collect $500 \mathrm{~kg}$ of regolith for processing. Using a load calibrated bucket, Centaur 2 would dig until the strain gauges read that the bucket is full, without wasting energy trying to fill an already full bucket. After the load is scooped into the bucket, the exact quantity of regolith is measured so that Centaur 2 autonomously knows how many digging cycles are needed to complete the mission.

The strain gauge setup on the Digger could also be used for an exploration mission. A basic understanding of a soil can be developed from measuring the excavation forces involved in extracting it. From this information it is possible to infer certain properties of the material being excavated such as density, compaction and even composition. This information could then be used to set up mines or outposts.

The use of load sensing in excavation implements is important for sustained autonomous excavation. Load sensing allows a vehicle to perform the task of excavation without exceeding safe operating loads and without doing unnecessary work.

\section{REFERENCES}

1. NASA Johnson Space Center. Robonaut Mobility. [Online] http://robonaut.jsc.nasa.gov/mobility/

2. Balovnev, V. I.: "New Methods for Calculating Resistance to Cutting Soil", Amerind Publishing (Translation), P. Data, translator and Rosvuzizdat, New Delhi, Available from National Technical Information Service, Springfield, VA 22161, 1983 and 1963. 